\title{
Preparation of Phase-Pure M1 MoVTeNb Oxide Catalysts by Hydrothermal Synthesis-Influence of Reaction Parameters on Structure and Morphology
}

\author{
A. Celaya Sanfiz $\cdot$ T. W. Hansen $\cdot$ F. Girgsdies $\cdot$ \\ O. Timpe $\cdot$ E. Rödel $\cdot$ T. Ressler $\cdot$ A. Trunschke $\cdot$ \\ R. Schlögl
}

Published online: 17 June 2008

(C) The Author(s) 2008

\begin{abstract}
This work presents a detailed investigation of the preparation of $\mathrm{MoVTeNbO}_{x}$ catalysts by hydrothermal synthesis. Phase-pure synthesis of M1 has been achieved applying the metals in a molar ratio $\mathrm{Mo} / \mathrm{V} / \mathrm{Te} / \mathrm{Nb}=1 / 0.25 /$ $0.23 / 0.12$. Raman, UV/Vis spectroscopy, and SEM/EDX analysis show that the elements are inhomogeneously distributed in the initial suspension that is formed after mixing the metal salts in an aqueous medium. Iso- and heteropoly anions of molybdenum, free telluric acid as well as supramolecular polyoxometalate clusters are observed in the solution, whereas all metals have been found in the precipitate. Complete rearrangement of molecular building blocks under hydrothermal conditions is essential for formation of phase-pure materials. Optimized synthesis conditions with respect to temperature and time result in the formation of a precursor consisting of nano-structured M1 characterized by an extended periodic organization in the [001] direction and a fairly homogeneous distribution of the elements. Residual ammonium containing supramolecular species in the precursor result in the formation of phase mixtures during the subsequent crystallization by heat treatment in inert gas. Phase-pure M1 exhibits a distinct degree of flexibility with respect to the chemical composition that becomes obvious by incorporating $\mathrm{Nb}$ not exclusively into pentagonal bi-pyramidal units, but also
\end{abstract}

A. Celaya Sanfiz - T. W. Hansen - F. Girgsdies - O. Timpe ·

E. Rödel · A. Trunschke $(\varangle) \cdot$ R. Schlögl

Department of Inorganic Chemistry, Fritz Haber Institute of the

Max Planck Society, Faradayweg 4-6, 14195 Berlin, Germany

e-mail: trunschke@fhi-berlin.mpg.de

T. Ressler

Institute of Chemistry, Technische Universität Berlin, Sekr. C 2,

Strasse des 17. Juni 135, 10623 Berlin, Germany into octahedral coordinated positions as shown by EXAFS. Anisotropic growth of the needle-like M1 crystals has been observed during the final heat treatment performed at 873-923 $\mathrm{K}$ in inert atmosphere disclosing a potential method to control the catalytic properties of $\mathrm{MoVTeNbO}_{x}$ catalysts.

Keywords Hydrothermal synthesis $\cdot \mathrm{MoVTeNbO}_{x}$ catalyst $\cdot$ M1 phase $\cdot$ Propane oxidation

\section{Introduction}

Multi-metal oxides based on molybdenum, vanadium, tellurium, and niobium have been reported to achieve outstanding performance in the direct oxidation of propane to acrylic acid [1]. Despite their considerable chemical complexity, such materials basically consist of two orthorhombic phases known as M1 and M2 [2]. Minority phases like $\left(\mathrm{Mo}_{0.93} \mathrm{~V}_{0.07}\right)_{5} \mathrm{O}_{14}, \mathrm{MoO}_{3}$, and $\mathrm{TeMo}_{5} \mathrm{O}_{16}[3,4]$ are also formed depending on the preparation method and the activation procedure applied. In the M1 phase (ICSD 55097 [5]), corner-linked $\mathrm{MO}_{6}(\mathrm{M}=\mathrm{Mo}, \mathrm{V})$ octahedrons are assembled forming 6- and, 7-membered rings, partially accommodating $\mathrm{TeO}$ units [6-9]. Niobium has been postulated to be exclusively located in the center of a $\mathrm{MO}_{7}$ pentagonal bipyramidal unit sharing edges with the surrounding octahedrons [6, 9]. The (001) planes are congruently stacked along the [001] direction, forming a bronze-like structure similar to the structure of $\mathrm{Cs}_{0.7}\left(\mathrm{Nb}_{2.7} \mathrm{~W}_{2.3}\right) \mathrm{O}_{14}$ (ICSD 67974 [5]) [10]. The M2 phase differs from M1 by the absence of the pentagonal bi-pyramidal unit, and the 7-membered ring [6]. The formulae of the refined unit cells have been determined to be $\mathrm{Mo}_{7.8} \mathrm{~V}_{1.2} \mathrm{Te}_{0.937} \mathrm{NbO}_{28.9}$ for $\mathrm{M} 1$ and $\mathrm{Mo}_{4.31} \mathrm{~V}_{1.36} \mathrm{Te}_{1.81}$ $\mathrm{Nb}_{0.33} \mathrm{O}_{19.81}$ for $\mathrm{M} 2$, respectively [6]. 
Symbiosis between the two phases has been suggested to be responsible for maximum yield of acrylic acid or acrylonitrile in the oxidation or ammoxidation of propane, respectively $[11,12]$. Selective oxidation of propane has been assigned to M1. M2 on its own does not activate propane, but selectively oxidizes the propylene intermediate. Correlations between phase composition and catalytic properties are still actively debated [13-16]. However, it has been generally accepted that the high selectivity towards acrylic acid is associated with the M1 phase [3, 17]. Based on chemical experience, the unique catalytic properties of M1 have been attributed to the specific geometric arrangement of the metal centers in the (001) plane $[18,19]$. However, the molecular structure and dynamic nature of the active moiety on the M1 surface under conditions of propane oxidation, (673 K and up to $50 \mathrm{vol}-\%$ steam in the feed) still remain to be elucidated experimentally. For that purpose, synthesis of phase-pure M1 in larger batches is a basic prerequisite.

Generally, two different preparation methods have been used to synthesize MoVTeNb mixed oxides. By precipitation and fast evaporation of water from the precipitate suspended in the mother liquor, orange colored precursors are obtained. Subsequent calcination in air followed by annealing in inert atmosphere at high temperatures usually results in catalysts composed of several phases $[2,14,20]$. Purification by post-treatment with nitric acid [16] or $\mathrm{H}_{2} \mathrm{O}_{2}$ [21], gives access to phase-pure M1. However, the chemical composition of M1 might be affected by leaching [15].

Hydrothermal synthesis represents an alternative synthesis route to MoVTeNb oxide catalysts [22]. Usually the synthesis is performed at $\mathrm{T}=448 \mathrm{~K}$ in nitrogen atmosphere applying a synthesis time of $48 \mathrm{~h}$ [23-29].

López Nieto and co-workers conducted the synthesis under these conditions in a Teflon-lined stainless-steel autoclave using different metal-containing compounds and various nominal metal stoichiometries [23, 24, 27-29]. Generally, phase mixtures including $\mathrm{Mo}_{5} \mathrm{TeO}_{16}, \mathrm{MoO}_{3}$, $\mathrm{M}_{5} \mathrm{O}_{14}(\mathrm{M}=\mathrm{Mo}, \mathrm{V}, \mathrm{Nb}), \mathrm{Te}_{2} \mathrm{M}_{20} \mathrm{O}_{57}(\mathrm{M}=\mathrm{Mo}, \mathrm{V}, \mathrm{Nb})$, and $\mathrm{Te}_{0.33} \mathrm{MO}_{3.33}(\mathrm{M}=\mathrm{Mo}, \mathrm{V}, \mathrm{Nb})$ were obtained after heat treatment for $2 \mathrm{~h}$ at $873 \mathrm{~K}$ in nitrogen of the hydrothermally prepared precursor. The latter two phases correspond to M1 and M2, respectively, as originally denominated by Ushikubu et al. [2]. M1 has been achieved as the predominant phase using a nominal metal stoichiometry of $\mathrm{Mo} / \mathrm{V} / \mathrm{Te} / \mathrm{Nb}=1 / 0.2 / 0.17 / 0.17$ and oxalate/ molybdenum molar ratios in the range between 0.2 and 0.6 [29]. The as-synthesized metal stoichiometry of the M1-rich materials correspond to $\mathrm{Mo} / \mathrm{V} / \mathrm{Te} / \mathrm{Nb}=1 / 0.20-0.27 /$ $0.19-0.22 / 0.19-0.21$.

Applying a synthesis temperature of $448 \mathrm{~K}$ and a synthesis time of $48 \mathrm{~h}$, Ueda and co-workers prepared orthorhombic MoVTeNb mixed oxides in a stainless-steel autoclave equipped with a $70 \mathrm{~mL}$ Teflon inner beaker without stirring using a nominal stoichiometry of the metals of $\mathrm{Mo} / \mathrm{V} / \mathrm{Te} / \mathrm{Nb}=1 / 0.3 / 0.16 / 0.12$ and a molybdenum concentration of $0.76 \mathrm{M}$ [25]. The XRD patterns of the resulting dark blue powder indicate the formation of a basically amorphous material. However, one sharp peak close to $30^{\circ} 2 \theta$ probably due to elemental tellurium has also been observed. Heat treatment of the precursor in nitrogen at $873 \mathrm{~K}$ for $2 \mathrm{~h}$ resulted in the formation of a crystalline solid. The XRD patterns displayed all reflections of the orthorhombic M1 phase. Polycrystalline orthorhombic MoVTe [30] and MoV [31] oxides have also been prepared operating at the same synthesis temperature, but applying different metal ratios, molybdenum concentrations, and synthesis times, as well as separating undesired phases by manual sorting [30].

Selective synthesis of phase-pure M1 requires precise control of preparation parameters, such as temperature, metal salt concentration, metal stoichiometry, batch size, pressure, and redox potential of the synthesis mixture. The latter is determined by $\mathrm{pH}$, solvent, organic additives, and the nature of metal salt precursors. Moreover, different characteristics of a specific autoclave, e.g., wall material, volume, and heating/cooling regime have substantial influence on the crystallization behavior. These factors are well known in the synthesis of crystalline alumosilicates but have not yet been considered in the preparation of MoVTeNb oxides. In the present work, a systematic investigation of the hydrothermal preparation procedure of MoVTeNb mixed oxides has been undertaken. The arrangement of molecular building blocks in aqueous solution has been studied by Raman and UV/Vis spectroscopy. The development of short-range order during hydrothermal synthesis has been investigated by X-ray absorption spectroscopy, while the bulk and microstructure of precursors and heat-treated crystalline synthesis products have been analyzed by X-ray diffraction and electron microscopy, respectively. The hydrothermal synthesis was revealed to be the crucial synthesis step in the formation of nano-structured M1. The morphology of the final catalyst is governed by the conditions of the thermal treatment.

\section{Experimental}

\subsection{Preparation of MoVTeNb Mixed Oxides}

MoVTeNb mixed metal oxide catalysts have been prepared by hydrothermal synthesis using two different autoclaves. The technical parameters of these autoclaves are summarized in Table 1. The general preparation procedure is illustrated in Scheme 1. Ammonium heptamolybdate $\left(\mathrm{NH}_{4}\right)_{6}$ $\mathrm{Mo}_{7} \mathrm{O}_{24} \cdot 4 \mathrm{H}_{2} \mathrm{O}$ (Merck), vanadyl sulfate $\mathrm{VOSO}_{4} \cdot 5 \mathrm{H}_{2} \mathrm{O}$ 
(Riedel-deHäen), telluric acid $\mathrm{Te}(\mathrm{OH})_{6}$ (Aldrich), and ammonium niobium oxalate $\left(\mathrm{NH}_{4}\right)\left[\mathrm{NbO}\left(\mathrm{C}_{2} \mathrm{O}_{4}\right)_{2}\left(\mathrm{H}_{2} \mathrm{O}\right)_{2}\right]$. $3 \mathrm{H}_{2} \mathrm{O}$ (Aldrich) were used as starting materials to prepare the initial suspension that contains the metals in a molar ratio of $\mathrm{Mo} / \mathrm{V} / \mathrm{Te} / \mathrm{Nb}=1 / 0.25 / 0.23 / 0.12$. After replacing residual air by nitrogen, hydrothermal synthesis was carried out at temperatures between 373 and $448 \mathrm{~K}$ for $24-144 \mathrm{~h}$, producing autogeneous pressures between 4 and 9 bars. The obtained suspensions were centrifuged for $20 \mathrm{~min}$; the precipitate was washed with $100 \mathrm{~mL}$ of bidistilled water for $10 \mathrm{~min}$ and filtered under vacuum. Finally, the solid material was dried in a muffle furnace at $353 \mathrm{~K}$ for $16 \mathrm{~h}$ in air, resulting in the precursor material, referred to as $\mathrm{P}$ followed by a consecutive number.

Starting from the precursors, crystalline products have been obtained by heat treatment of $3 \mathrm{~g}$ of the precursor in inert gas with a flow of $100 \mathrm{~mL} / \mathrm{min}$ for $2 \mathrm{~h}$ at 873 or $923 \mathrm{~K}$ (heating rate $15 \mathrm{~K} / \mathrm{min}$ ), either with or without previous calcination in synthetic air $(100 \mathrm{~mL} / \mathrm{min})$ for $1 \mathrm{~h}$ at 548 or $598 \mathrm{~K}$ (heating rate $10 \mathrm{~K} / \mathrm{min}$ ). The heat

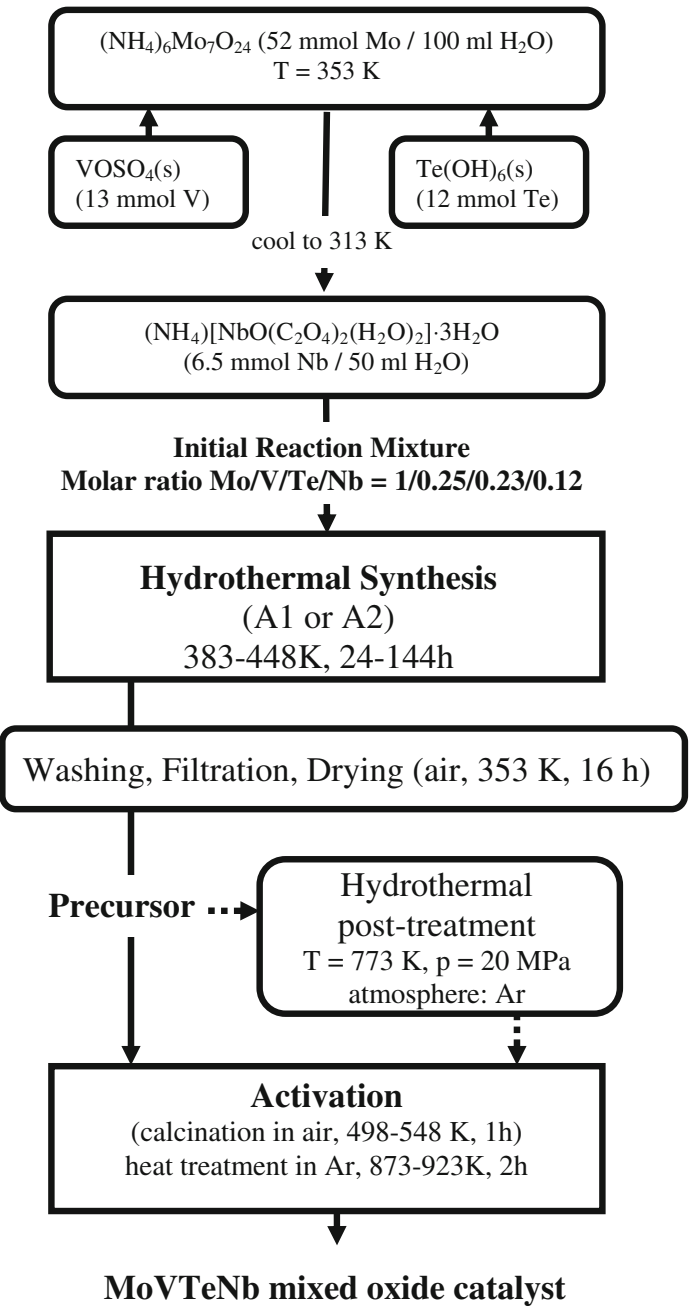

Scheme 1 Hydrothermal synthesis of MoVTeNb mixed oxides
Table 1 Specifications of the autoclaves used

\begin{tabular}{lll}
\hline Parameter & Autoclave 1 (A1) & Autoclave 2 (A2) \\
\hline Volume & $200 \mathrm{~mL}$ & $300 \mathrm{~mL}$ \\
Wall material & Hastelloy C276 & Teflon \\
Stirring & $250 \mathrm{rpm}$ & No control \\
Cooling & Water cooling $(1.6 \mathrm{~K} / \mathrm{min})$ & Manually $(6.0 \mathrm{~K} / \mathrm{min})$ \\
\end{tabular}

treatments were carried out in a rotating oven. The crystalline reaction products are denominated as $\mathrm{C}$ followed by the consecutive number of the corresponding precursor.

\subsection{Characterization}

Molecular species in the initial solutions and precipitates were studied by Raman spectroscopy performed on a Labram I (Dilor) instrument equipped with a confocal microscope (Olympus). A notch filter (Kaiser Optical) was applied to cut off the laser-line and the Rayleigh scattering up to $150 \mathrm{~cm}^{-1}$. The spectrometer is equipped with a CCD camera (1024*298 diodes) that is Peltier cooled to $243 \mathrm{~K}$ to reduce the thermal noise. A He/Ne laser (Melles Griot) was used to excite the Raman scattering at $632 \mathrm{~nm}$. Using a slit width of $200 \mu \mathrm{m}$ and a 1800 grating gives a spectral resolution of $2.5 \mathrm{~cm}^{-1}$. For the solution experiments the laser beam was directed through the glass reaction vessel into the solution. UV/Vis spectra have been recorded on a PerkinElmer Lambda 950 UV/Vis-NIR spectrometer.

Phase composition of the catalysts was determined by X-ray diffraction performed on a STOE STADI-P transmission diffractometer equipped with a focussing primary Ge(111) monochromator and a position sensitive detector, using $\mathrm{Cu}-\mathrm{K} \alpha_{1}$ radiation. The diffraction patterns of the activated materials were analyzed with the "TOPAS" software (v.2.1, Bruker AXS).

The short-range order in the M1 precursor and in crystalline M1 has been investigated by X-ray absorption spectroscopy. The XAS measurements were performed in transmission mode at the Mo K edge (19.999 keV), Nb K edge (18.986 keV), VK edge (5.465 keV), and Te $\mathrm{L}_{\mathrm{III}}$ edge (4.314 keV) at beamlines X1 and E4 at the Hamburger Synchrotronstrahlungslabor, HASYLAB. For investigation of $\mathrm{Mo}$ and $\mathrm{Nb}, 30 \mathrm{mg}$ of boron nitride was mixed with ca. $8 \mathrm{mg}$ sample, ground, and pressed into a pellet of $5 \mathrm{~mm}$ in diameter under one ton of pressure. For investigation of $\mathrm{V}$ and Te, $100 \mathrm{mg}$ of polyethylene was mixed with $5 \mathrm{mg}$ sample, ground and pressed at a force of 2 tons into a pellet $13 \mathrm{~mm}$ in diameter. The resulting edge jump amounted to $\Delta \mu \sim 0.5$ at the Mo K edge and Nb K edge, $\Delta \mu \sim 0.02$ at the VK edge, and $\Delta \mu \sim 0.1$ at the Te $\mathrm{L}_{\mathrm{III}}$ edge. Data processing and analysis were performed with the software package WinXAS 3.1 [32]. 
Morphology studies and shape analysis were performed using scanning electron microscopy. A Hitachi S-5200 with a PGT Spirit EDX system and a Hitachi S-4800 with an EDAX Genesis EDX detector were used. EDX studies in the SEMs were carried out with an accelerating voltage of $10 \mathrm{kV}$ while images were acquired at $2 \mathrm{kV}$ to optimize surface resolution. For SEM investigations, the samples were deposited on carbon tape without any pretreatment. From the SEM images, size distributions of the M1 needles have been obtained by measuring the lengths and diameters of more than $300 \mathrm{M} 1$ needles.

Nitrogen physisorption at $77 \mathrm{~K}$ was measured using an AUTOSORB-1-C physisorption/chemisorption analyzer (Quantachrome). Specific surface areas have been calculated from the adsorption isotherms using the BET method.

Thermal analysis was performed using a STA 449C Jupiter apparatus (Netzsch). Precursors have been heated in He atmosphere (flow rate $100 \mathrm{~mL} / \mathrm{min}$ ) applying a heating rate of $10 \mathrm{~K} / \mathrm{min}$. The produced gases were analyzed using an OmniStar quadrupole mass spectrometer (Pfeiffer Vacuum).

\section{Results and Discussion}

\subsection{Molecular Species in the Initial Suspension}

Metal salt concentration and metal stoichiometry strongly influence the phase composition of molybdenum based mixed oxides prepared by hydrothermal synthesis [22, 24, 25, 28, 29, 31, 33]. These parameters have been kept constant, because the present study mainly addresses the thermodynamic and kinetic parameters of M1 synthesis. The preparation procedure (Scheme 1) differs slightly from the routines described in the literature [22]. Ammonium heptamolybdate was dissolved in bidistilled water at $353 \mathrm{~K}$, resulting in a colorless solution with a $\mathrm{pH}$ of 5.3. Subsequently, vanadyl sulfate as a powder was added at $353 \mathrm{~K}$. The color of the mixture $(\mathrm{pH}=3.05)$ changed into dark violet. Finally, solid telluric acid was added at the same temperature, forming a light brown slurry ( $\mathrm{pH}=2.18$ ). Afterwards, the MoVTe slurry was cooled to $313 \mathrm{~K}$ and a solution of ammonium niobium oxalate in bidistilled water $(313 \mathrm{~K}, \mathrm{pH}=0.8)$ was added, resulting in further precipitation. Before introduction into the autoclave, the dispersion $(313 \mathrm{~K}, \mathrm{pH}=1.69)$ was stirred for $10 \mathrm{~min}$. The observation of color changes and precipitation processes during the preparation procedure described above reflects the formation and rearrangement reactions of molecular building blocks happening in this early stage of the synthesis. Raman spectra of reference solutions and the binary MoV solution are shown in Fig. 1. The spectrum of the colorless telluric acid solution $(296 \mathrm{~K}, \mathrm{pH}=3.7$,
$[\mathrm{Te}]=0.138 \mathrm{M}$ ) exhibits a single peak at $644 \mathrm{~cm}^{-1}$ due to $v(\mathrm{Te}-\mathrm{O})$ vibrations (Fig. 1a) [34]. The aqueous solution of vanadyl sulfate $(298 \mathrm{~K}, \mathrm{pH}=1.86, \quad[\mathrm{~V}]=0.198 \mathrm{M})$ (Fig. 1b) displays a strong band at 980 and a shoulder at $996 \mathrm{~cm}^{-1}$ associated to superimposed $\mathrm{V}=\mathrm{O}$ and $\mathrm{S}=\mathrm{O}$ stretching vibrations of solvated vanadyl ions [35]. The Raman spectrum of ammonium heptamolybdate in aqueous solution $(333 \mathrm{~K}, \mathrm{pH}=5.2,[\mathrm{Mo}]=0.6 \mathrm{M})$ is characterized by bands at 937 and $893 \mathrm{~cm}^{-1}$ due to the presence of $\left[\mathrm{Mo}_{7} \mathrm{O}_{24}\right]^{6-}$ species (Fig. 1c) [36]. Bands at 942, 919, and $570 \mathrm{~cm}^{-1}$ assigned to $\mathrm{Nb}=\mathrm{O}$ and $\mathrm{Nb}-\mathrm{O}$ stretching vibrations, respectively, were observed with the ammonium niobium oxalate solution $(296 \mathrm{~K}, \quad \mathrm{pH}=0.8$, $[\mathrm{Nb}]=0.5 \mathrm{M})$ (Fig. 1d) [37].

When vanadium and tellurium are added successively to the solution of ammonium heptamolybdate, significant changes in the Raman spectra are observed. Figure 1e shows the Raman spectrum taken after addition of $0.11 \mathrm{mmol}$ vanadium as vanadyl sulfate in $10 \mathrm{~mL}$ bidistilled water $(\mathrm{Mo} / \mathrm{V}=1 / 0.03)$. The bands due to ammonium heptamolybdate are reduced in intensity and two new bands at 824 and $874 \mathrm{~cm}^{-1}$ appear. The band at $874 \mathrm{~cm}^{-1}$ is reminiscent of the peaks observed in Raman spectra of supra-molecular polyoxomolybdates or mixed molybdenum-vanadium clusters $[38,39]$. Such clusters are composed of $\left\{(\mathrm{Mo}) \mathrm{Mo}_{5}\right\}$ structural units, which can be regarded as structural building block of the M1 structure.

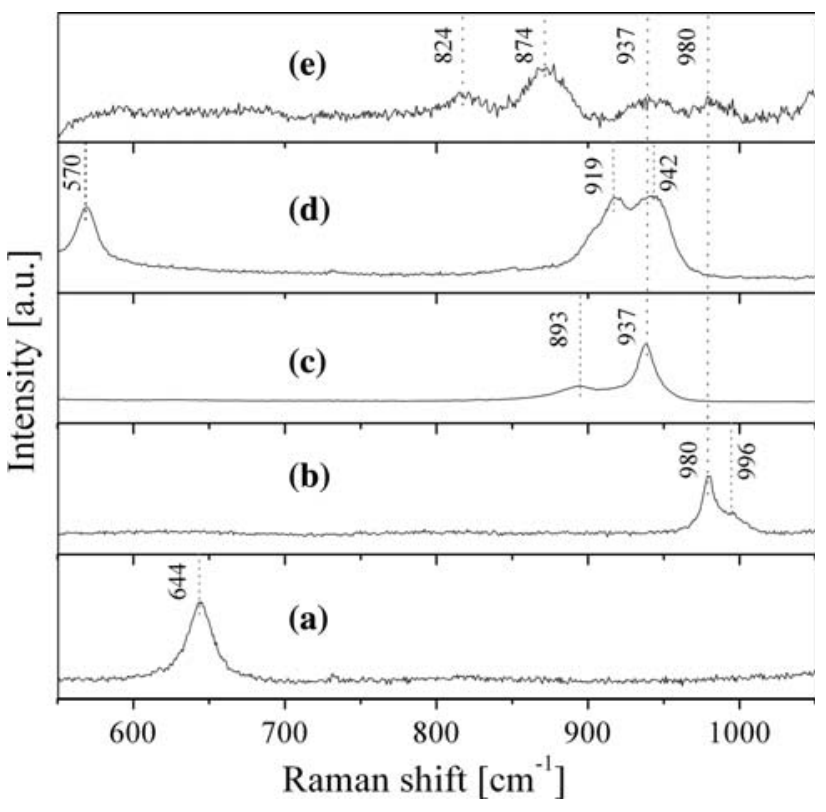

Fig. 1 Raman spectra of aqueous solutions of (a) $\mathrm{Te}(\mathrm{OH})_{6}(296 \mathrm{~K}$, $\mathrm{pH}=3.7,[\mathrm{Te}]=0.138 \mathrm{M}),(\mathbf{b}) \mathrm{VOSO}_{4} \cdot 5 \mathrm{H}_{2} \mathrm{O}(298 \mathrm{~K}, \mathrm{pH}=1.86$, $[\mathrm{V}]=0.198 \mathrm{M}),(\mathbf{c})\left(\mathrm{NH}_{4}\right)_{6} \mathrm{Mo}_{7} \mathrm{O}_{24} \cdot 4 \mathrm{H}_{2} \mathrm{O}(333 \mathrm{~K}, \mathrm{pH}=5.2,[\mathrm{Mo}]=$ $0.6 \mathrm{M})$, (d) $\left(\mathrm{NH}_{4}\right)\left[\mathrm{NbO}\left(\mathrm{C}_{2} \mathrm{O}_{4}\right)_{2}\left(\mathrm{H}_{2} \mathrm{O}\right)_{2}\right] \cdot 3 \mathrm{H}_{2} \mathrm{O} \quad(296 \mathrm{~K}, \mathrm{pH}=0.8$, $[\mathrm{Nb}]=0.5 \mathrm{M})$, and (e) $\left(\mathrm{NH}_{4}\right)_{6} \mathrm{Mo}_{7} \mathrm{O}_{24} \cdot 4 \mathrm{H}_{2} \mathrm{O}+\mathrm{VOSO}_{4} \cdot 5 \mathrm{H}_{2} \mathrm{O}$ $(\mathrm{T}=298 \mathrm{~K},[\mathrm{Mo}]=0.33 \mathrm{M}$, molar ratio $\mathrm{Mo} / \mathrm{V}=1 / 0.03)$ 
These units consist of a central pentagonal bipyramidally coordinated Mo atom surrounded by five edge-sharing $\mathrm{MoO}_{6}$ octahedrons. The UV/Vis spectrum of the supramolecular polyoxometalate cluster $\mathrm{Mo}^{\mathrm{VI}}{ }_{72} \mathrm{~V}_{30}^{\mathrm{IV}}$ in aqueous solution is characterized by two bands at 689 (w) and 510 (vs) nm [39]. A related spectrum has also been observed during preparation of a mixed MoV oxide [40]. The binary MoV solution shows similar bands at about 690 and $530 \mathrm{~nm}$ (Fig. 2b) providing further evidence for the formation of mixed MoV polyoxometalates.

The Raman spectrum of the final binary solution that contains molybdenum and vanadium in a molar ratio of $\mathrm{Mo} / \mathrm{V}=1 / 0.25$ (not shown) is of very low quality due to the dark color of the solution. However, the general spectroscopic patterns and, therefore, the nature of the molecular species in solution are not changed with increasing vanadium concentration.

After the addition of tellurium, precipitation occurs, making interpretation of the Raman spectrum difficult due to superposition of bands originating from both solution and precipitate. Therefore, the solid was removed by filtration.

The Raman spectrum of the MoVTe filtrate is shown in Fig. 3a. In addition to the bands at 874 and $980 \mathrm{~cm}^{-1}$ due to the presence of polyoxometalate clusters and vanadyl sulfate, respectively, bands at 644,946 and $1010 \mathrm{~cm}^{-1}$ appear. The band at $946 \mathrm{~cm}^{-1}$ could be attributed to the formation of $\left[\mathrm{TeMo}_{6} \mathrm{O}_{24}\right]^{6-}$ Anderson-type heteropolyanions $[14,41,42]$. The band at $1010 \mathrm{~cm}^{-1}$ may indicate partial substitution of Mo by V in the Anderson anion [42], which is also supported by a shift of the absorption maximum in the UV/Vis spectrum to lower energies (Fig. 2c). Molybdo-tellurates containing vanadium have been

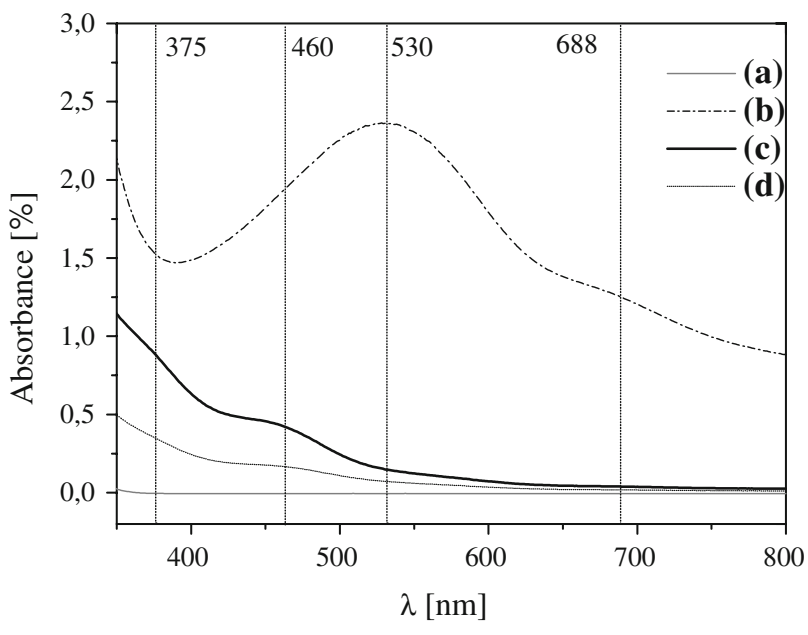

Fig. 2 UV/Vis spectra of aqueous solutions of $\left(\right.$ a) $\left(\mathrm{NH}_{4}\right)_{6} \mathrm{Mo}_{7} \mathrm{O}_{24} \cdot 4 \mathrm{H}_{2} \mathrm{O}$ $(298 \mathrm{~K}, \quad \mathrm{pH}=5.2, \quad[\mathrm{Mo}]=0.3 \mathrm{M}), \quad$ (b) $\quad\left(\mathrm{NH}_{4}\right)_{6} \mathrm{Mo}_{7} \mathrm{O}_{24} \cdot 4 \mathrm{H}_{2} \mathrm{O}+$ $\mathrm{VOSO}_{4} \cdot 5 \mathrm{H}_{2} \mathrm{O}(\mathrm{T}=298 \mathrm{~K}, \mathrm{pH}=3.05,[\mathrm{Mo}]=0.3 \mathrm{M}$, molar ratio $\mathrm{Mo} / \mathrm{V}=1 / 0.25)$, (c) MoVTe filtrate, and (d) MoVTeNb filtrate

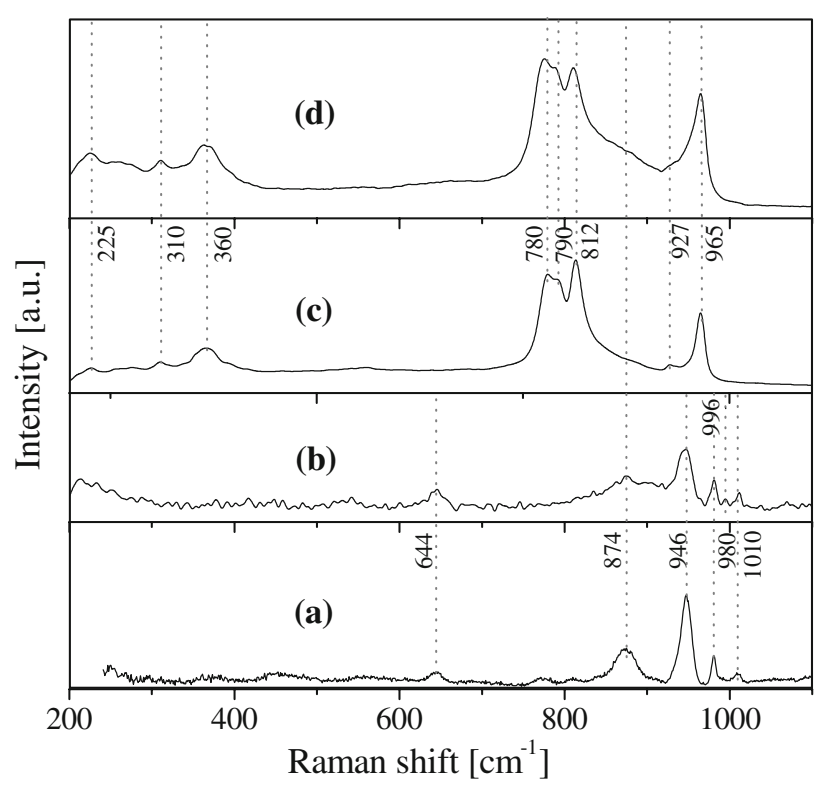

Fig. 3 Raman spectra of the (a) MoVTe filtrate, (b) MoVTeNb filtrate, (c) MoVTe precipitate, and (d) MoVTeNb precipitate

reported to show absorption below $400 \mathrm{~nm}$ in the UV/Vis spectrum [42]. However, due to similar band positions and intensity ratios in the Raman spectra of $\left[\mathrm{Mo}_{7} \mathrm{O}_{24}\right]^{6-}$ and $\left[\mathrm{TeMo}_{6} \mathrm{O}_{24}\right]^{6-}$, the coexistence of heptamolybdate anions in the solution cannot be excluded. On the other hand, mixed $\mathrm{Mo}^{\mathrm{V}} / \mathrm{Mo}^{\mathrm{VI}}$ polyoxomolybdate clusters, such as $\left(\mathrm{NH}_{4}\right)_{42}\left[\mathrm{Mo}^{\mathrm{VI}}{ }_{72} \mathrm{Mo}_{60}^{\mathrm{V}} \mathrm{O}_{372}\left(\mathrm{CH}_{3} \mathrm{COO}\right)_{30}\left(\mathrm{H}_{2} \mathrm{O}\right)_{72}\right]$ ca. $300 \mathrm{H}_{2} \mathrm{O}$ ca. $10 \mathrm{CH}_{3} \mathrm{COONH}_{4}$ exhibit bands at 215,260 , and $450 \mathrm{~nm}$ in the UV/Vis spectrum [38]. The spectrum of the MoVTe filtrate (Fig. 2c) showing a band at $450 \mathrm{~nm}$ and absorption below $300 \mathrm{~nm}$, could therefore also be interpreted in terms of the formation of molybdenum-blue-type clusters. The latter interpretation would be in agreement with the existence of the band at $874 \mathrm{~cm}^{-1}$ in the Raman spectrum, which is also characteristic for such clusters [38]. Finally, the peak at $644 \mathrm{~cm}^{-1}$ indicates the presence of free telluric acid in the MoVTe filtrate.

The dried white precipitate that has been separated from the MoVTe filtrate was also analyzed by Raman spectroscopy (Fig. 3c) and SEM-EDX (Fig. 4a, Table 2). A Mo/Te molar ratio of $\sim 6$ was measured at different spots of the white solid (Fig. 4a), which is consistent with the metal ratio in an Anderson-type heteropolyanion $\left[\mathrm{TeMo}_{6} \mathrm{O}_{24}\right]^{6-}$. Particles containing substantial amounts of vanadium have also been detected. The Raman spectrum of the solid shows bands at 225, 310, 360, 780, 790, 812, 927, and $965 \mathrm{~cm}^{-1}$.

After addition of the ammonium niobium oxalate solution to the ternary MoVTe mixture, further precipitation occurs. Raman spectra of the filtrated solution and the precipitate have been recorded separately (Fig. 3b, d). The Raman spectrum of the MoVTeNb solution shows 

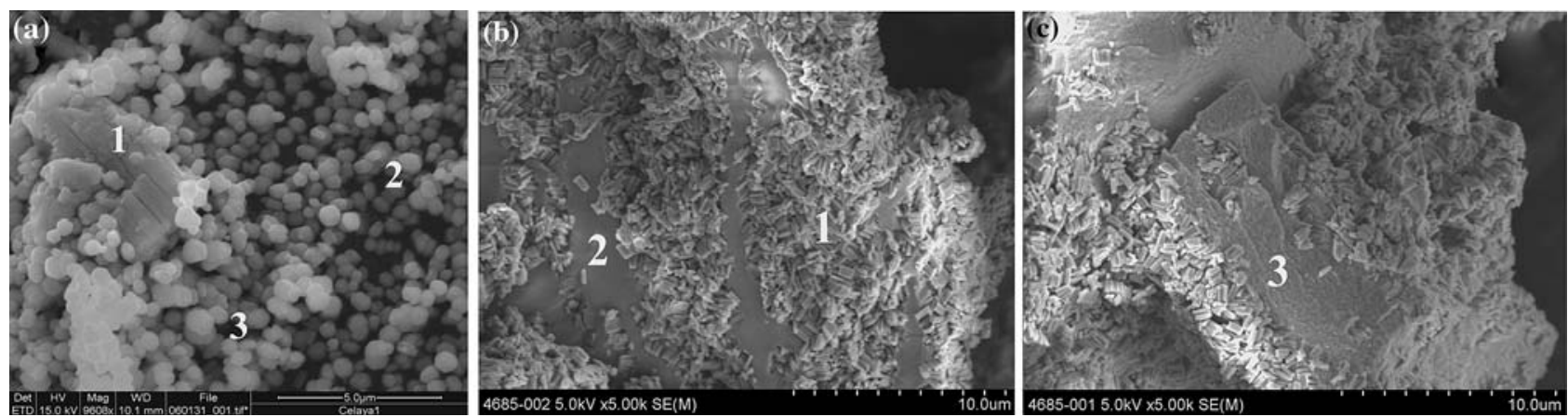

Fig. 4 SEM images of (a) the MoVTe precipitate obtained after filtration of the ternary slurry (synthesis with molar ratio $\mathrm{Mo} / \mathrm{V} /$ $\mathrm{Te}=1 / 0.25 / 0.23$ ), and (b and c) of the MoVTeNb precipitate

Table 2 Elemental analysis (at.-\%) of the MoVTe and MoVTeNb precipitate by EDX at different spots

\begin{tabular}{lllrrrl}
\hline & Spot & $\mathrm{Mo}$ & $\mathrm{V}$ & $\mathrm{Te}$ & $\mathrm{Nb}$ & $\mathrm{Mo} / \mathrm{Te}$ ratio \\
\hline MoVTe precipitate & 1 & 67 & 26 & 7 & 0 & 9.0 \\
& 2 & 84 & 2 & 14 & 0 & 5.6 \\
& 3 & 85 & 2 & 13 & 0 & 6.5 \\
MoVTeNb precipitate & 1 & 80 & 1 & 15 & 14 & 5.3 \\
& 2 & 66 & 8 & 13 & 13 & 5.1 \\
& 3 & 54 & 7 & 13 & 26 & 4.2 \\
\hline
\end{tabular}

SEM images of both materials are shown in Fig. 4

similarities to that of the MoVTe solution (Fig. 3a). Bands due to $\mathrm{Nb}-\mathrm{O}$ stretching vibrations are absent in the spectrum of the filtrate, indicating that most of the added niobium was precipitated. Figure $3 \mathrm{~d}$ shows the Raman spectrum of the MoVTeNb precipitate that is similar to the spectrum of the MoVTe precipitate.

In summary, Raman and UV/Vis spectroscopy, together with SEM-EDX analysis indicate that the individual elements are distributed rather inhomogeneously in the initial suspension. Although the interpretation of Raman and UV/ Vis spectra of the complex mixture is not unambiguous, giant polyoxometalate clusters containing the pentagonal bipyramidal structure, iso- and heteropolyanions of molybdenum and free telluric acid are supposed to be present in the solution. The pre-formed precipitate contains all the elements.

\subsection{Hydrothermal Synthesis}

Catalyst synthesis aimed at the formation of a desired crystal structure is preferably performed under hydrothermal conditions. Although the structural rearrangements occurring during hydrothermal synthesis are concealed by the "black box" autoclave, the synthesis can be optimized by applying different reaction conditions and appropriate adjustment of the chemical properties of the reaction obtained after filtration of the final mixture (synthesis with molar ratio $\mathrm{Mo} / \mathrm{V} / \mathrm{Te} / \mathrm{Nb}=1 / 0.25 / 0.23 / 0.12$ ). Elemental composition at the spots marked is shown in Table 2

medium. Moreover, it is well known that technical parameters of a specific autoclave, such as wall material, vessel size, stirring system, cooling and heating facilities, exert significant influence by affecting heat transfer, wall effects, homogeneity, and crystallization behavior. Until now, less attention has been paid to the hydrothermal conditions in preparation of $\mathrm{MoVTeNb}$ mixed oxides. However, these parameters might have a crucial influence on phase and chemical composition of the resulting catalysts and finally on their catalytic properties, particularly due to the considerable chemical flexibility of the orthorhombic M1 structure [22].

In the following, the impact of temperature, reaction time, and technical parameters of the autoclave on M1 synthesis has been studied. For this purpose, the initial reaction mixture, prepared as described above, was transferred into two different autoclaves, referred to as A1 and A2, respectively. The technical parameters of the two autoclaves differing in wall material, batch size and cooling system are summarized in Table 1. An overview of the experimental conditions applied and the final phase composition of the activated mixed oxides obtained is given in Table 3. Precursor materials are denominated as " $\mathrm{P}$ " and the corresponding activated catalysts are denominated as " $\mathrm{C}$ ".

The phase composition of the final crystalline material differs depending on autoclave, synthesis temperature and reaction time used (Table 3). Applying standard hydrothermal conditions $(\mathrm{T}=448 \mathrm{~K}, \mathrm{t}=48 \mathrm{~h})$ in autoclave $\mathrm{A} 1$, precursor materials P1-P5 have been obtained, which could reproducibly be crystallized into phase-pure M1 (C1-C5). If the same reaction conditions were applied in autoclave A2, the synthesis results in a precursor of a phase mixture (P6/C6 in Table 3). However, synthesis of phasepure M1 succeeded in A2 after optimization of the reaction temperature. The latter was varied between 383 and $448 \mathrm{~K}$ (autogeneous pressures between 4 and 9 bar) (Fig. 5), keeping the synthesis time constant at $96 \mathrm{~h}$. The optimum synthesis temperature in A2 was found to be $403 \mathrm{~K}$ (P10). 
Table 3 Hydrothermal conditions and phase composition of the activated catalysts; the nominal stoichiometry applied in hydrothermal synthesis corresponds to $\mathrm{Mo} / \mathrm{V} / \mathrm{Te} /$ $\mathrm{Nb}=1 / 0.25 / 0.23 / 0.124$, with the exception of $\mathrm{P} 7(\mathrm{Mo} / \mathrm{V} / \mathrm{Te} /$ $\mathrm{Nb}=1 / 0.25 / 0.15 / 0.124)$

\begin{tabular}{|c|c|c|c|c|c|}
\hline \multirow{2}{*}{$\frac{\text { Precursor/catalyst }}{\mathrm{P} 1 / \mathrm{C} 1}$} & \multirow{2}{*}{$\frac{\text { Code }}{1760 / 1761}$} & \multirow{2}{*}{$\begin{array}{l}\text { Autoclave } \\
\text { A1 }\end{array}$} & \multirow{2}{*}{$\begin{array}{l}\text { Hydrothermal conditions } \\
448 \mathrm{~K}, 48 \mathrm{~h}\end{array}$} & \multicolumn{2}{|c|}{ Phase composition [\%] } \\
\hline & & & & M1 & 100 \\
\hline $\mathrm{P} 2 / \mathrm{C} 2$ & $929 / 939$ & & & & \\
\hline $\mathrm{P} 3 / \mathrm{C} 3$ & $1885 / 1886$ & & & & \\
\hline $\mathrm{P} 4 / \mathrm{C} 4$ & $1422 / 1434$ & & & & \\
\hline $\mathrm{P} 5 / \mathrm{C} 5$ & $1422 / 1650$ & & & & \\
\hline \multirow[t]{3}{*}{ P6/C6 } & $2431 / 2501$ & $\mathrm{~A} 2$ & $448 \mathrm{~K}, 48 \mathrm{~h}$ & M1 & 58 \\
\hline & & & & M2 & 37 \\
\hline & & & & $\mathrm{Mo}_{5} \mathrm{O}_{14}$ & 5 \\
\hline \multirow[t]{4}{*}{$\mathrm{P} 7 / \mathrm{C} 7$} & $2445 / 2488$ & & $448 \mathrm{~K}, 48 \mathrm{~h}$ & M1 & 47 \\
\hline & & & & M2 & 11 \\
\hline & & & & $\mathrm{Mo}_{5} \mathrm{O}_{14}$ & 25 \\
\hline & & & & $\mathrm{V}_{0.95} \mathrm{Mo}_{0.97} \mathrm{O}_{5}$ & 17 \\
\hline \multirow[t]{4}{*}{$\mathrm{P} 8 / \mathrm{C} 8$} & $3961 / 3984$ & & $403 \mathrm{~K}, 24 \mathrm{~h}$ & M1 & 53 \\
\hline & & & & M2 & 14 \\
\hline & & & & $\mathrm{Mo}_{5} \mathrm{O}_{14}$ & 23 \\
\hline & & & & $\mathrm{TeMo}_{5} \mathrm{O}_{16}$ & 10 \\
\hline \multirow[t]{3}{*}{$\mathrm{P} 9 / \mathrm{C} 9$} & $3791 / 3792$ & & $403 \mathrm{~K}, 48 \mathrm{~h}$ & M1 & 51 \\
\hline & & & & M2 & 23 \\
\hline & & & & $\mathrm{Mo}_{5} \mathrm{O}_{14}$ & 26 \\
\hline $\mathrm{P} 10 / \mathrm{C} 10$ & $3241 / 3673$ & & $403 \mathrm{~K}, 96 \mathrm{~h}$ & M1 & 100 \\
\hline \multirow[t]{2}{*}{$\mathrm{P} 11 / \mathrm{C} 11$} & $3648 / 3779$ & & $403 \mathrm{~K}, 144 \mathrm{~h}$ & M1 & 90 \\
\hline & & & & M2 & 10 \\
\hline \multirow[t]{3}{*}{$\mathrm{P} 12 / \mathrm{C} 12$} & $3665 / 3695$ & & $383 \mathrm{~K}, 96 \mathrm{~h}$ & M2 & 29 \\
\hline & & & & $\mathrm{Mo}_{5} \mathrm{O}_{14}$ & 60 \\
\hline & & & & $\mathrm{TeMo}_{5} \mathrm{O}_{16}$ & 11 \\
\hline \multirow[t]{2}{*}{$\mathrm{P} 13 / \mathrm{C} 13$} & $3777 / 3778$ & & $423 \mathrm{~K}, 96 \mathrm{~h}$ & M1 & 86 \\
\hline & & & & M2 & 14 \\
\hline \multirow[t]{4}{*}{$\mathrm{P} 14 / \mathrm{C} 14$} & $3298 / 3303$ & & $448 \mathrm{~K}, 96 \mathrm{~h}$ & M1 & 38 \\
\hline & & & & M2 & 41 \\
\hline & & & & $\mathrm{Mo}_{5} \mathrm{O}_{14}$ & 8 \\
\hline & & & & $\mathrm{V}_{0.95} \mathrm{Mo}_{0.97} \mathrm{O}_{5}$ & 13 \\
\hline
\end{tabular}

At this temperature, phase-pure M1 has been obtained after activation (C10). Below this temperature, M1 is not formed, but $\mathrm{M} 2, \mathrm{Mo}_{5} \mathrm{O}_{14}$, and $\mathrm{TeMo}_{5} \mathrm{O}_{16}$. Increasing the temperature further to 423 and $448 \mathrm{~K}$, results in the formation of $\mathrm{M} 1 / \mathrm{M} 2$ (C13), and $\mathrm{M} 1 / \mathrm{M} 2 / \mathrm{Mo}_{5} \mathrm{O}_{14} / \mathrm{V}_{0.95}$ $\mathrm{Mo}_{0.97} \mathrm{O}_{5}$ phase mixtures $(\mathrm{C} 14)$, respectively.

Furthermore, the synthesis time of the hydrothermal treatment has been varied between 24 and $144 \mathrm{~h}$, keeping the optimized synthesis temperature constant at $403 \mathrm{~K}$ (Fig. 6). The complexity of the crystalline phase mixtures decreases with increasing reaction time resulting in phasepure M1 after $96 \mathrm{~h}$ (C10). However, an extended reaction time of $144 \mathrm{~h}$, again results in a M1/M2 phase mixture (C11).

The diffraction patterns of the various precursor materials obtained under the different hydrothermal reaction conditions show different characteristics. Generally, XRD patterns of the precursor materials synthesized in A1 exhibit a broad peak at $22^{\circ} 2 \theta$, a peak of very low intensity at $45^{\circ} 2 \theta$, and two ill-defined features around $8^{\circ}$ and $27^{\circ} 2 \theta$ (see for example P2 in Fig. 7a). The reflection at $22^{\circ} 2 \theta$ indicates the presence of long-range ordering of either, M1, $\mathrm{M} 2$, or a $\mathrm{Mo}_{5} \mathrm{O}_{14}$-type phase in the [001] direction. Ordering along other crystallographic directions is hardly developed as indicated by the width of the other features, which are observed at diffraction angles where the reflections of the M1 structure are expected (Fig. 8) [5, 8]. Activation of the precursor prepared in A1 leads to highly crystalline phase-pure M1 (see for example C2 in Fig. 8a). The XRD patterns of crystalline M1 materials C1-C5 fit satisfactorily with the structural model of M1 refined by DeSanto et al. (ICSD 55097) [5], showing differences only with respect to the peak intensities, which indicates deviant metal site occupancy (Fig. 8c). 


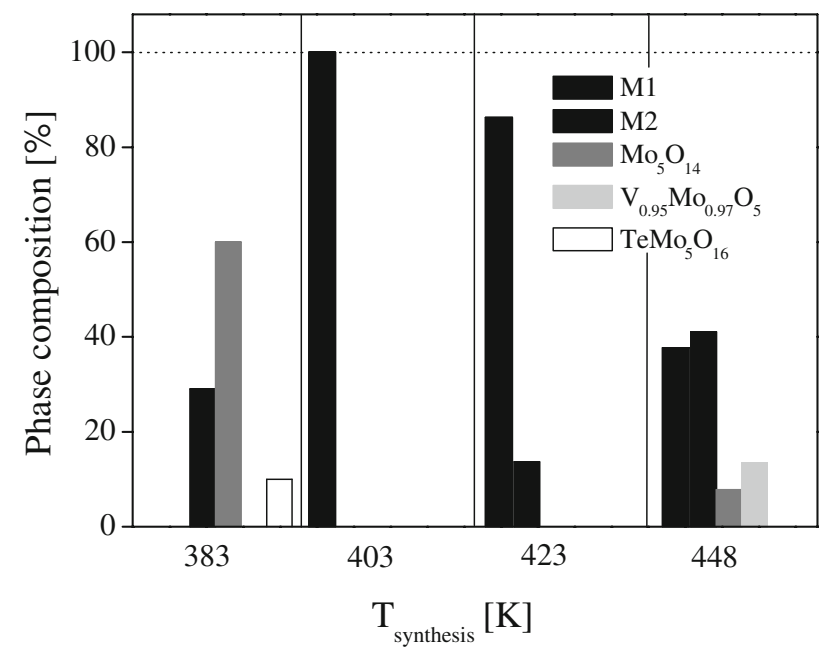

Fig. 5 Phase composition of catalysts prepared in A2 at different temperatures; synthesis time $=96 \mathrm{~h}$

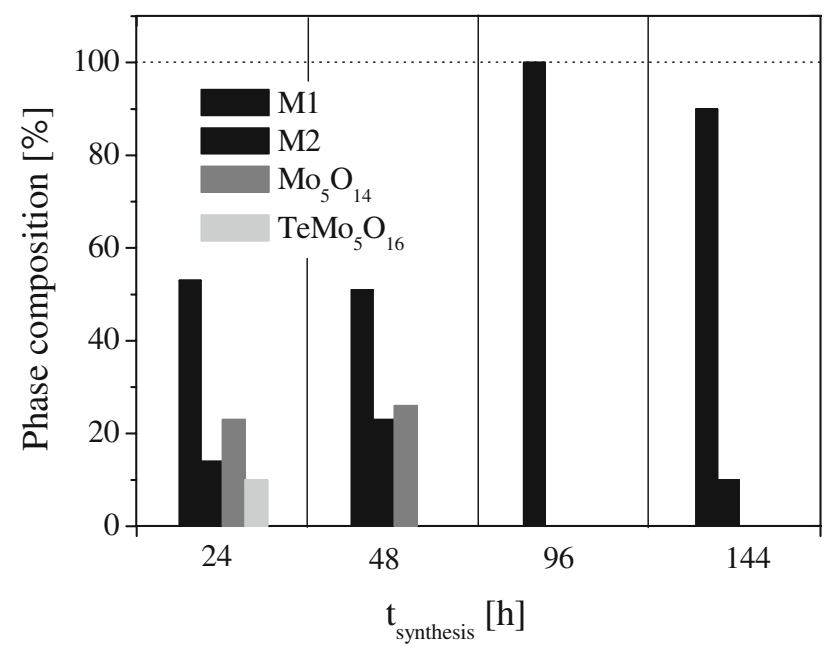

Fig. 6 Phase composition of catalysts prepared in A2 at $403 \mathrm{~K}$ and different synthesis times

In addition to the peaks described above for the M1 precursor materials, sharp peaks at $8.3^{\circ}, 9.7^{\circ}, 10.0^{\circ}, 12.4^{\circ}, 18.6^{\circ}$, $24.9^{\circ}, 27.1^{\circ}, 27.6^{\circ}, 30.4^{\circ}$, and $38.3^{\circ} 2 \theta$ appear in the XRD patterns of precursor materials leading to phase mixtures of $\mathrm{M} 1, \mathrm{M} 2, \mathrm{M}_{5} \mathrm{O}_{14}$-type $(\mathrm{M}=\mathrm{Mo}, \mathrm{V}$ and/or $\mathrm{Nb})$ structures, and/or $\mathrm{V}_{0.95} \mathrm{Mo}_{0.97} \mathrm{O}_{5}$ (Table 3, Fig. 7b-h). The peak at $8.3^{\circ}$ $2 \theta$ may be assigned to a supra-molecular vanadium compound $\left(\mathrm{NH}_{4}\right)_{8}\left(\mathrm{~V}_{19} \mathrm{O}_{41}(\mathrm{OH})_{9}\right)\left(\mathrm{H}_{2} \mathrm{O}\right)_{11}$ (ICSD 063213) [43], and the peak at $10.0^{\circ} 2 \theta$ may indicate the formation of ammonium octamolybdate $\left(\mathrm{NH}_{4}\right)_{6} \mathrm{Mo}_{8} \mathrm{O}_{27} \cdot 4 \mathrm{H}_{2} \mathrm{O}$ (ICSD 2017) [44]. The peaks at $9.7^{\circ}, 12.4^{\circ}, 18.6^{\circ}$, and $30.4^{\circ} 2 \theta$ can be assigned to $\left(\mathrm{NH}_{4}\right)_{2}\left(\mathrm{Mo}_{4} \mathrm{O}_{13}\right)$ (ICSD 068562), whereas the peaks at $27.6^{\circ}$ and $38.3^{\circ} 2 \theta$ are due to the presence of elemental tellurium. Furthermore, the presence of $\mathrm{Nb}_{2} \mathrm{Te}_{4} \mathrm{O}_{13}$ (ICSD 90371) cannot be excluded due to the presence of additional peaks at $24.9^{\circ}$ and $27.1^{\circ} 2 \theta$.
Precursors P8, P9, P11, and P13 (Fig. 7b, c, e, f) have identical XRD fingerprints, differing only in the intensity of the peak at $8.3^{\circ} 2 \theta$. As mentioned above, this peak may originate from a residual supra-molecular vanadium compound with $\mathrm{NH}_{4}{ }^{+}$as the counter-ion. The variety of phases in the activated catalysts increases with increasing intensity of this peak in the patterns of the precursor.

Figure $7 \mathrm{~g}$ and h show a slightly different XRD fingerprint with a peak at $10.0^{\circ} 2 \theta$ assigned to crystalline ammonium octamolybdate. The presence of this phase in the precursor may correlate with the formation of $\mathrm{V}_{0.95} \mathrm{Mo}_{0.97} \mathrm{O}_{5}$, which is obtained after the activation process in both cases $(\mathrm{C} 14, \mathrm{C} 7)$.

The presence of ammonium containing phases in the precursor materials leading to phase mixtures after activation is supported by thermoanalysis of the M1 precursor $\mathrm{P} 4$ and the multi-phase precursor P8, respectively. Two steps of mass loss appear in the TG curves of both precursors (Fig. 9). The mass loss of $15 \%$ of P4 is exclusively due to release of water. Traces of nitrogen containing compounds were not detected. In contrast, the mass loss of $7 \%$ observed in case of $\mathrm{P} 8$ is partially due to desorption of ammonia. The two losses observed at $388 \mathrm{~K}$ and $578 \mathrm{~K}$ are mainly associated with the release of water and oxygen. However, the second mass loss is also due to the decomposition of residual nitrogen containing compounds $\left(\mathrm{N}_{2}\right.$ $(\mathrm{m} / \mathrm{e}=28), \mathrm{NO}(\mathrm{m} / \mathrm{e}=30))$. Traces of $\mathrm{CO}_{2}(\mathrm{~m} / \mathrm{e}=44)$ are released at $490 \mathrm{~K}$ and $690 \mathrm{~K}$.

Obviously, nanostructure and phase composition of the precursor material predetermine the final phase composition of the catalyst obtained after activation in inert gas at high temperatures. The entire disruption of the metalligand coordination in the initial metal salts and complete rearrangement of the coordination geometry around the central metal atoms are presumably necessary requirements for crystallization of phase-pure M1 during the subsequent activation step. As long as, e.g., ammonium containing phases are observed in the precursor, the crystallization into a phase-pure M1 catalyst fails and additional phases are formed.

\subsection{Homogeneity and Microstructure of the Precursor Materials}

Phase-pure crystalline mixed oxides characteristically exhibit a high spatial homogeneity in their chemical composition. The homogeneous distribution of elements in phase-pure M1 is already reflected in the precursor as evidenced by EDX in the scanning electron microscopy. The standard deviation of the elemental analysis by EDX including numerous spots is lowest for the precursor of single-phase M1 (Fig. 10a). As expected, the standard deviation increases with increasing phase variety. Therefore, in 
Fig. 7 XRD patterns of precursors, (a) P2, (b) P11, (c) P13, (d) P6, (e) P9, (f) P8, (g) P14, and (h) P7

$\left(\mathrm{NH}_{4}\right)_{8}\left(\mathrm{~V}_{19} \mathrm{O}_{41}(\mathrm{OH})_{9}\right)\left(\mathrm{H}_{2} \mathrm{O}\right)_{11}$, $\bullet\left(\mathrm{NH}_{4}\right)_{6} \mathrm{Mo}_{8} \mathrm{O}_{27} \cdot 4 \mathrm{H}_{2} \mathrm{O}$, * M1 precursor. The resulting phase composition of each precursor after activation is indicated right in the figure in [\%]

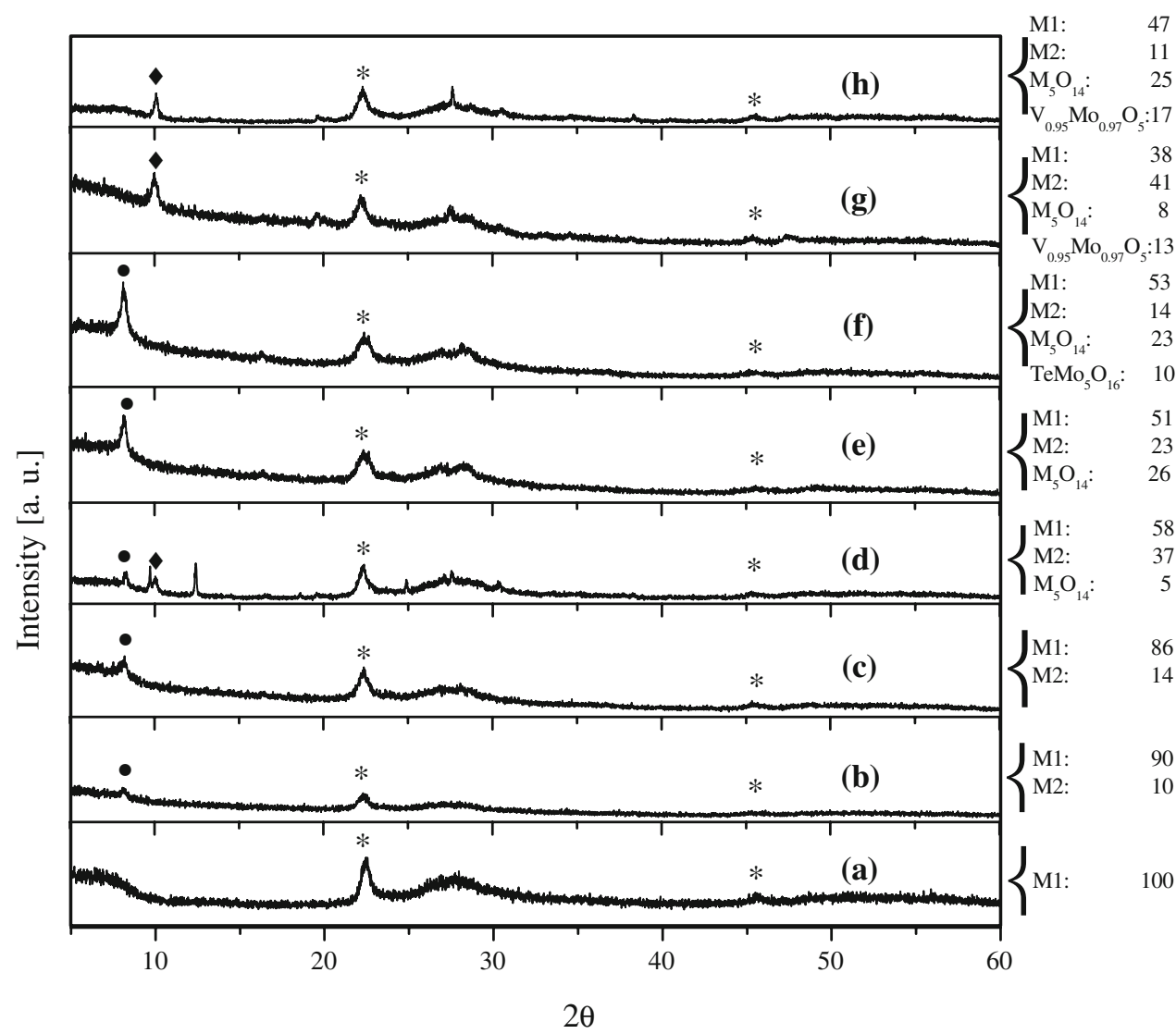

expected phase purity after activation. Compared to precursors leading to phase mixtures, the M1 precursor shows a strikingly increased niobium content. This increased $\mathrm{Nb}$ content is also evident from SEM/EDX analysis of the activated catalyst (Fig. 10b). Since the activated material is highly crystalline, the presence of $\mathrm{Nb}$ in amorphous fractions of the material can be excluded. The metal stoichiometry in the activated $\mathrm{M} 1$ corresponds to $\mathrm{Mo}_{6.24} \mathrm{~V}_{1.41} \mathrm{Te}_{1.76} \mathrm{Nb}_{2.35} \mathrm{O}_{x}$ for the catalyst $\mathrm{C} 1$. Compared to the unit cell formula normalized to niobium $\mathrm{Mo}_{7.8} \mathrm{~V}_{1.2} \mathrm{Te}_{0.94} \mathrm{Nb}_{1} \mathrm{O}_{28.9}$ given in the literature [5], the $\mathrm{Nb}$ content of M1 prepared in this work is more than two times higher than in the M1 phase analyzed by DeSanto et al. This increased $\mathrm{Nb}$ content is exclusively observed for the phase-pure M1 catalysts, but not for the phase mixtures and their precursors.

\subsection{Development of Short-Range Order During Hydrothermal Synthesis and Activation}

The M1 structure contains 13 crystallographic metal sites (Fig. 11). According to combined neutron and synchrotron powder diffraction data, the four metals occupy certain sites either preferred or exclusively [5]. EXAFS analysis has been performed on phase-pure M1 C1. The data quality obtained at the $\mathrm{V} \mathrm{K}$ edge and $\mathrm{Te} \mathrm{L}_{\mathrm{III}}$ edge was not addition to the XRD patterns, the analysis of the local bulk elemental distribution can also be used in evaluating the potential of as-synthesized precursor materials in view of the 
Fig. 9 TG-MS of precursor materials; (a) M1 precursor P4 and (b) precursor of a phase mixture P8
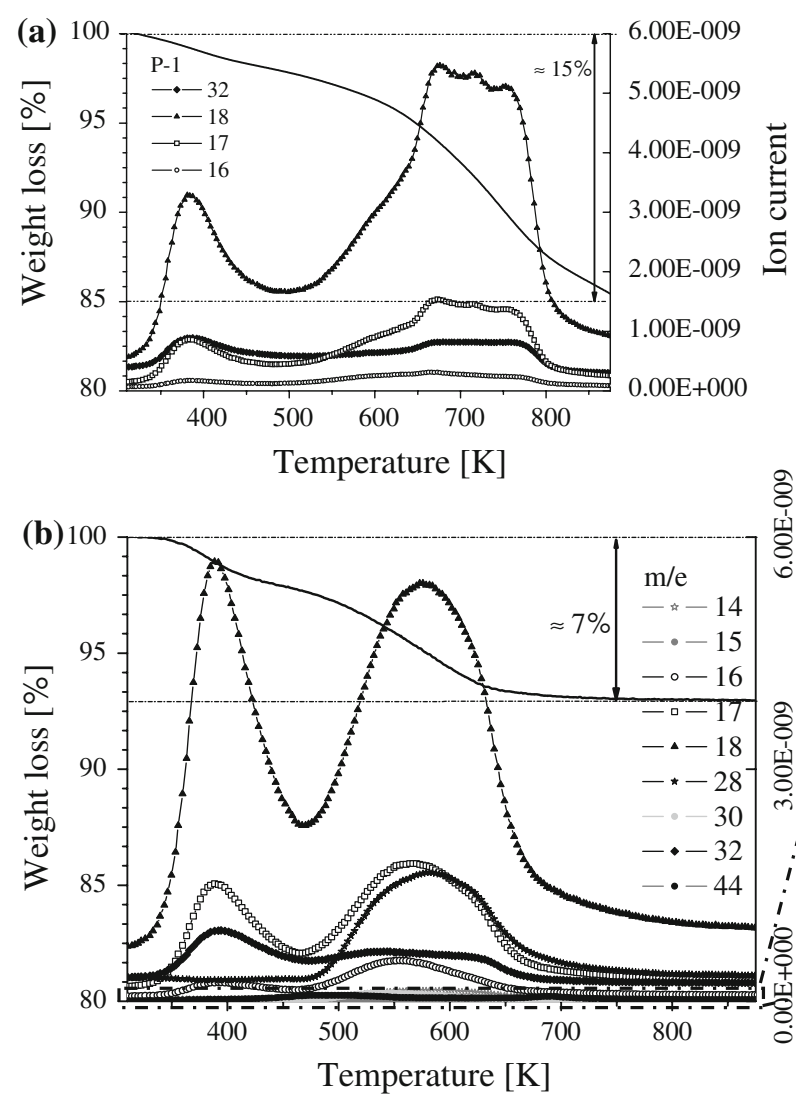
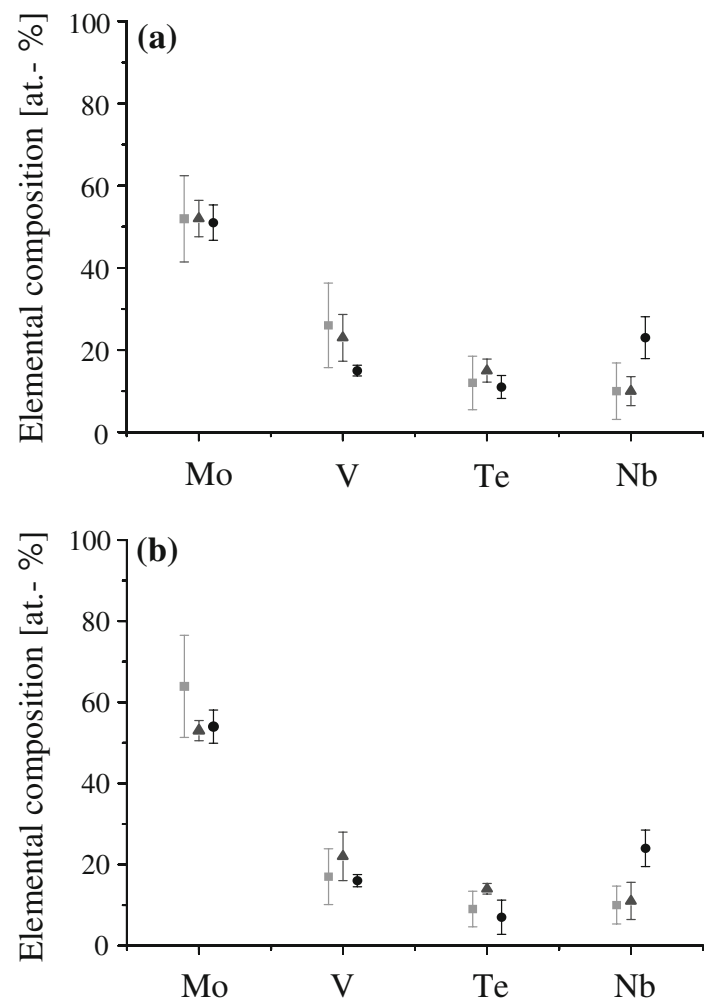

Fig. 10 Elemental composition of (a) single-, bi- and multi-phase precursors and (b) single, bi, multi-phase activated catalysts as determined by EDX. phase-pure M1; $\boldsymbol{\Delta}$ bi-phase materials; multi-phase materials. The bars represent the standard deviation sufficient for reliable analysis, but local coordination of Mo and $\mathrm{Nb}$ in both precursor and activated materials have been investigated. Of particular interest is the metal-metal shell in the EXAFS spectra, because this is directly correlated to the distance between neighboring metals and characteristic for the coordination geometry. An approximate classification of metal-metal distances in the M1 structure is given in Fig. 11. As observed in the EXAFS spectra at the Mo and $\mathrm{Nb} \mathrm{K}$ edges, the characteristic bond length distribution of the metal-oxygen and the metal-metal shell of the M1 phase is already established in the precursor (Fig. 12). The pseudo-radial distribution functions shown in Fig. 12 are not phase-shift corrected, and, therefore, the peaks are shifted by approximately $-0.4 \AA$ with respect to the crystallographic distances. The Fourier transform of the EXAFS signal at the $\mathrm{Nb} \mathrm{K}$ edge of the precursor material has a large peak at about $3 \AA$ that corresponds to the short metal-metal distance between the pentagonal bipyramidal coordination and the center of the surrounding octahedrons (Fig. 12a). In agreement with XRD, the higher amplitude in the metal-metal shells of the activated material compared to the precursor can be attributed to ongoing crystallization. At the Mo K edge (Fig. 12b), a second peak is observed at about $3.8 \AA$, which corresponds to longer metal-metal distances, typical for either distances between central atoms in octahedrons, or the interlayer Mo-M 
b

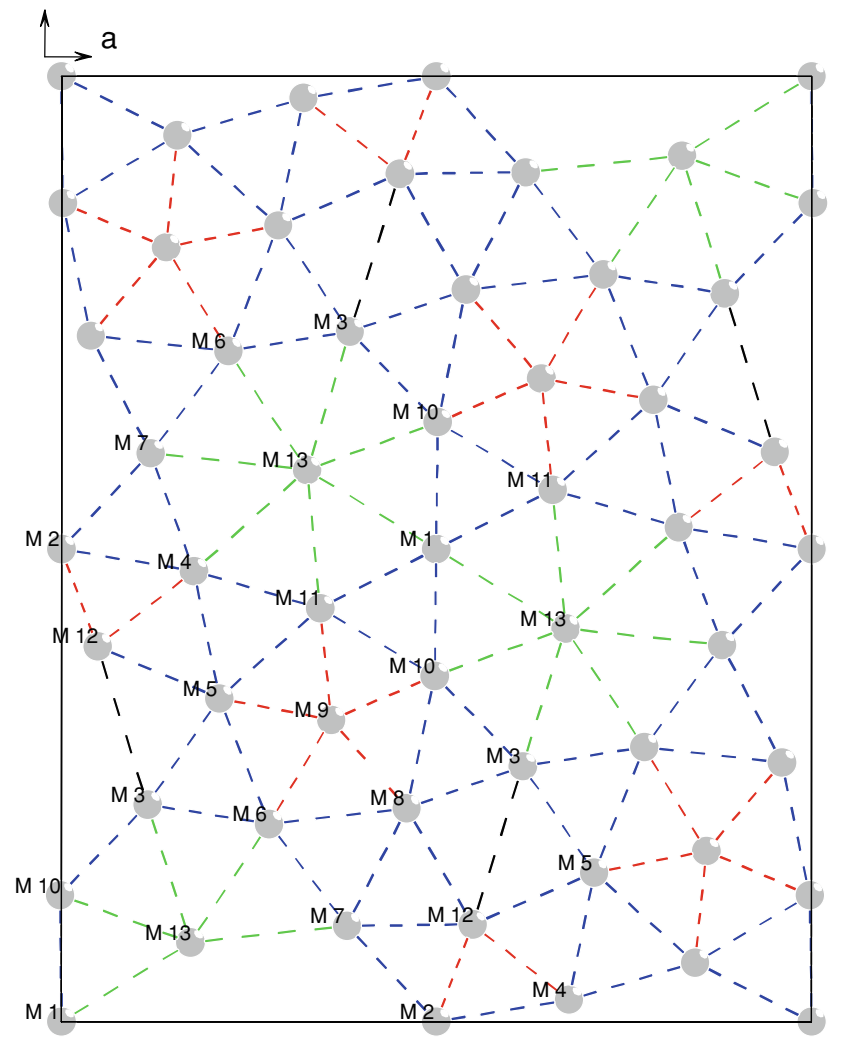

Fig. 11 Classification of average metal-metal distances in the M1 structure [6] (oxygen positions not shown): red: $2.9-3.5 \AA$, blue:

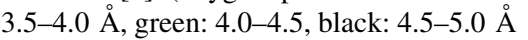

distance in [001] direction. In EXAFS spectra measured at the $\mathrm{Nb} \mathrm{K}$ edge, the strong amplitude in the metal-metal shell around the $\mathrm{Nb}$ centers at about $3 \AA$ indicates the presence of many short metal-metal distances implying preferential pentagonal bipyramidal coordination of niobium. Additionally, a broad shoulder appears at about $3.8 \AA$, which is present in the precursor and more pronounced in the activated material (Fig. 12a). This shoulder is much stronger than in simulations assuming exclusive pentagonal bi-pyramidal coordination of $\mathrm{Nb}$. Taking the high niobium content of $\mathrm{C} 1$ into account, which is inconsistent with the unit cell formula of a M1 containing $\mathrm{Nb}$ only in pentagonal bipyramidal positions [5, 8], EXAFS supplementary indicates that $\mathrm{Nb}$ is additionally located in octahedral positions.

\subsection{Post-Treatment of Multi-Phase Precursors}

Decomposition of the metal salts and complete rearrangement of molecular building blocks has been shown to be essential in hydrothermal synthesis of phase-pure M1. Control of process parameters is required to achieve this. Under standard conditions $(\mathrm{T}=448 \mathrm{~K}, \mathrm{t}=48 \mathrm{~h})$, the
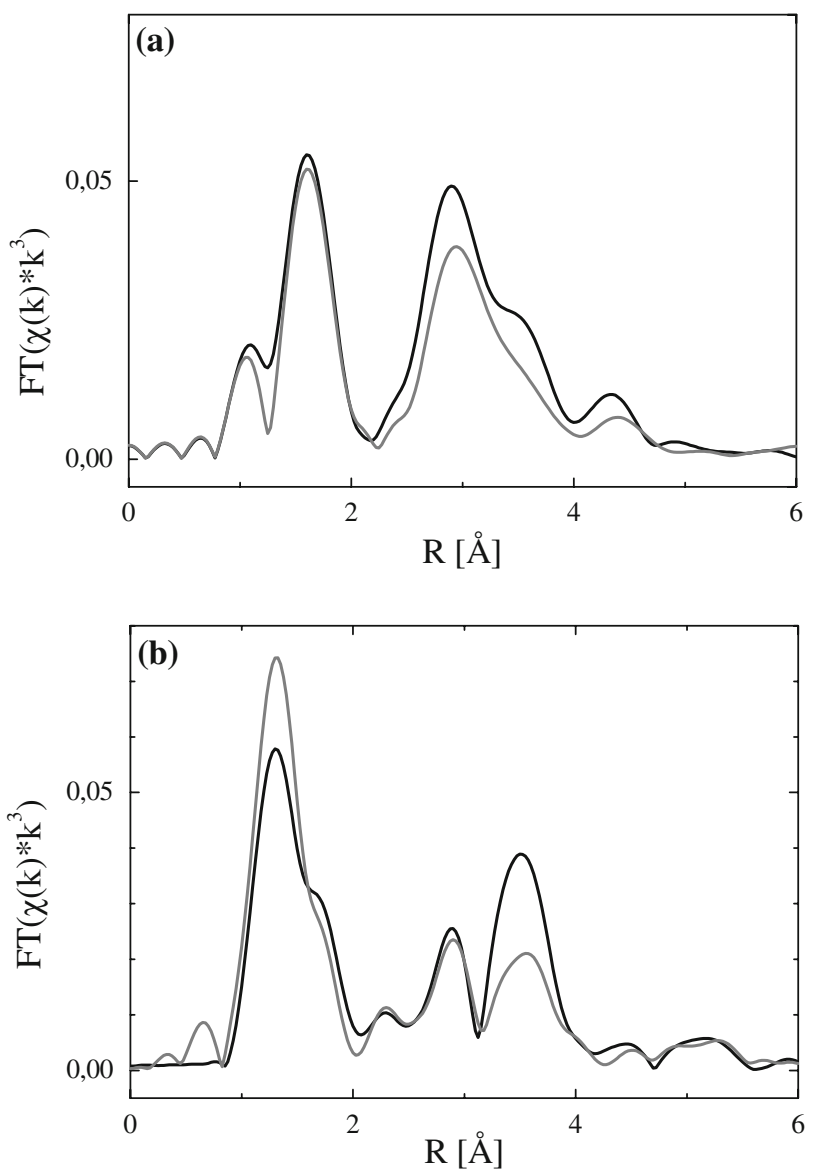

Fig. 12 Fourier transformed (not phase-shift corrected) of (a) the $\mathrm{Nb}$ $\mathrm{K}$ edge $\chi(\mathrm{k}) * \mathrm{k}^{3}$ and $(\mathbf{b})$ the Mo K edge $\chi(\mathrm{k}) * \mathrm{k}^{3}$ of the precursor (gray) and activated phase-pure M1 (black). The peaks are shifted by approx. $-0.4 \AA$ with respect to crystallographic distances

reconstruction succeeds more or less efficiently depending on the technical parameters of the autoclave. In Fig. 13a, diffraction patterns of a multi-phase precursor with a content of residual ammonium octamolybdate is shown. In the absence of oxygen, this precursor has been subjected to steam at $773 \mathrm{~K}$ and a pressure of $20 \mathrm{MPa}$ for $2 \mathrm{~h}$. The resulting material shows the typical $\mathrm{X}$-ray diffraction patterns of nano-structured M1 (Fig. 13b). Performing the usual thermal activation in argon at $673 \mathrm{~K}$, the steamtreated precursor crystallizes into phase-pure M1 (Fig. 13c) indicating a comparatively high thermodynamic stability of M1 under the high temperature and high pressure applied, compared to other phases, such as $\mathrm{M}_{5} \mathrm{O}_{14}$-type $(\mathrm{M}=\mathrm{Mo}$, $\mathrm{V}$ and/or $\mathrm{Nb}$ ) structures, or M2.

\subsection{Activation}

Activation in inert atmosphere at high temperatures is necessary, on the one hand, to obtain long-range order of the material and, on the other hand, to create catalytic activity. In the present work, different activation conditions 


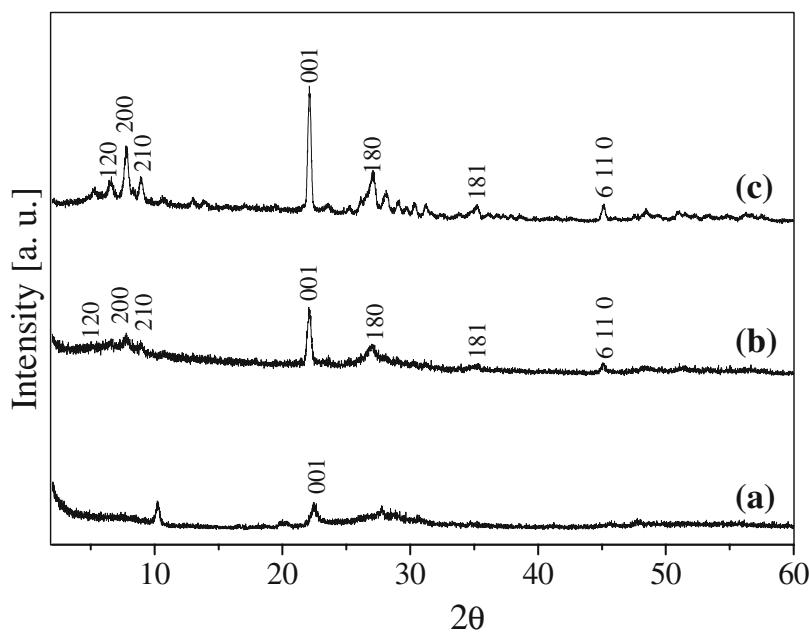

Fig. 13 XRD patterns of (a) a multi-phase precursor (catalyst code 2392) that crystallizes during heat treatment in Ar at $873 \mathrm{~K}$ into $55 \%$ $\mathrm{M} 1,31 \% \mathrm{M} 2$, and $14 \% \mathrm{Mo}_{5} \mathrm{O}_{14}$, (b) the precursor after hydrothermal post-treatment at $773 \mathrm{~K}$ in presence of steam (catalyst code 2902) and (c) the activated steam-treated material (catalyst code 3057)

have been applied to precursors prepared in A1 in order to study the influence of the activation conditions on the microstructure of the final catalyst. Irrespective of the temperature applied in the thermal treatment in an inert atmosphere $(873$ or $923 \mathrm{~K}$ ), and whether preceding calcination in air ( 548 or $498 \mathrm{~K}$ ) was performed, the bulk of the final catalyst is exclusively composed of M1, confirming the observation described above that the M1 phase is established during hydrothermal synthesis. To a certain extent, the specific surface area may be adjusted by the thermal activation parameters (Table 4). Different from the general expectation, the BET surface area increases with increasing activation temperature. In Fig. 14, SEM images of two phase-pure M1 catalysts activated at 873 or $923 \mathrm{~K}$, respectively, are shown. From these images, the typical needle-shape morphology of the M1 crystals is evident. The results of a shape analysis based on measuring approximately 400 needles are presented in Fig. 15. The distribution of the length of the needles in the two catalysts (Fig. 15a) is very similar. Evidently, in the present

Table 4 Influence of the heat treatment on BET surface area of crystalline phase-pure M1 catalysts synthesized in A1

\begin{tabular}{llll}
\hline Catalyst & $\begin{array}{l}\text { Calcination in } \\
\text { synthetic air }\end{array}$ & $\begin{array}{l}\text { Activation in } \\
\mathrm{Ar}\end{array}$ & $\begin{array}{l}\text { BET } \\
{\left[\mathrm{m}^{2} / \mathrm{g}\right]}\end{array}$ \\
\hline $\mathrm{C} 1$ & $548 \mathrm{~K}, 1 \mathrm{~h}$ & $873 \mathrm{~K}, 2 \mathrm{~h}$ & 1 \\
$\mathrm{C} 2$ & - & $873 \mathrm{~K}, 2 \mathrm{~h}$ & 2 \\
$\mathrm{C} 4$ & $598 \mathrm{~K}, 1 \mathrm{~h}$ & $923 \mathrm{~K}, 2 \mathrm{~h}$ & 4 \\
\hline
\end{tabular}

experiments the length was predetermined by the hydrothermal synthesis. This observation is consistent with the XRD results indicating that long-range ordering in the [001] direction is already established in the precursor material. Further growth of the needles in the [001] direction during the activation step cannot be excluded. However, in the temperature range applied (873-923 K), no influence of the temperature on the length of the needles was observed. In contrast, an anisotropic growth of the basal (001) plane has been observed. This is reflected in an increased mean diameter of the needles in phase-pure M1 activated at higher temperature (Fig. 15b). Apparently, the parameters of the heat treatment could be used to control the aspect ratio in the final phase-pure catalyst, which may have implications on the catalytic activity in propane oxidation. However, the effect observed for the two catalysts needs further systematic elucidation.
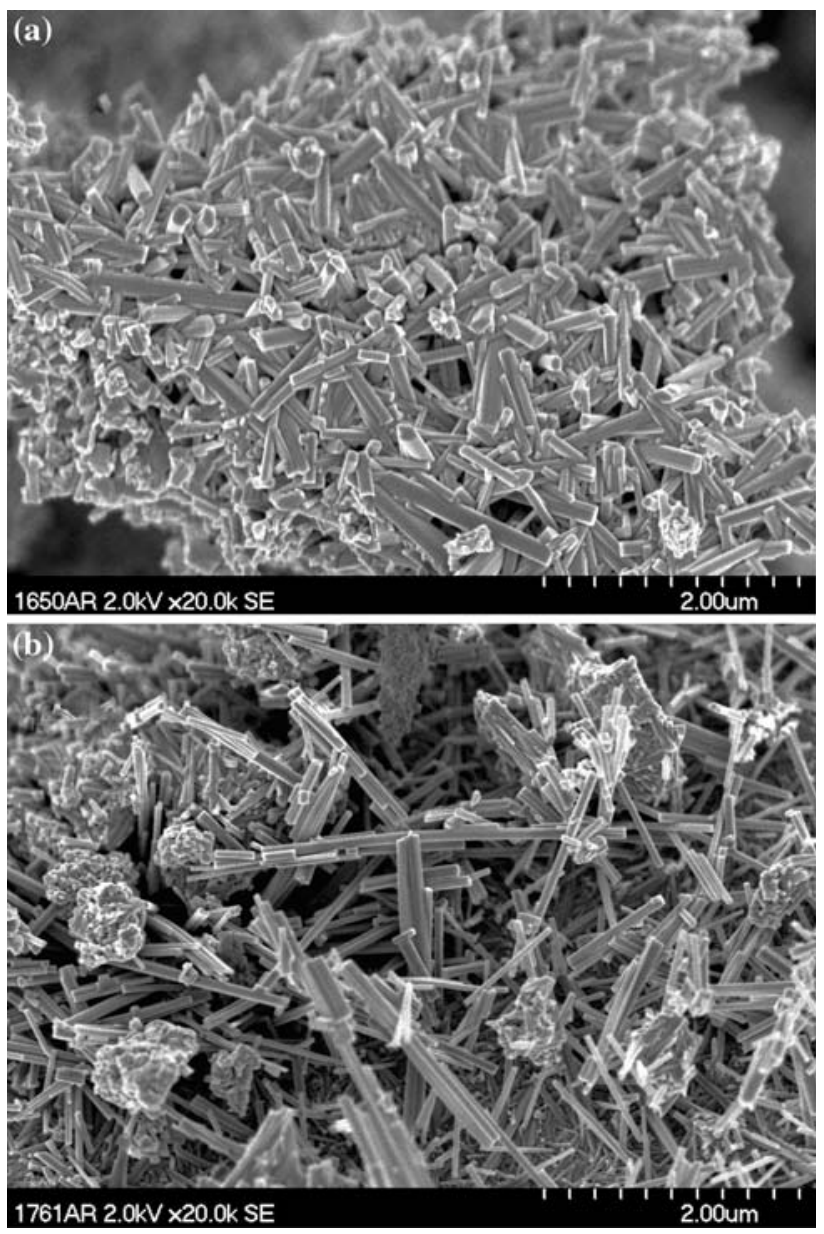

Fig. 14 SEM images of phase-pure catalysts treated at different temperatures; (a) calcination in air at $598 \mathrm{~K}$ followed by activation in argon at $923 \mathrm{~K}$ (C5) and (b) calcination in air at $548 \mathrm{~K}$ followed by activation in argon at $873 \mathrm{~K}(\mathrm{C} 1)$ 

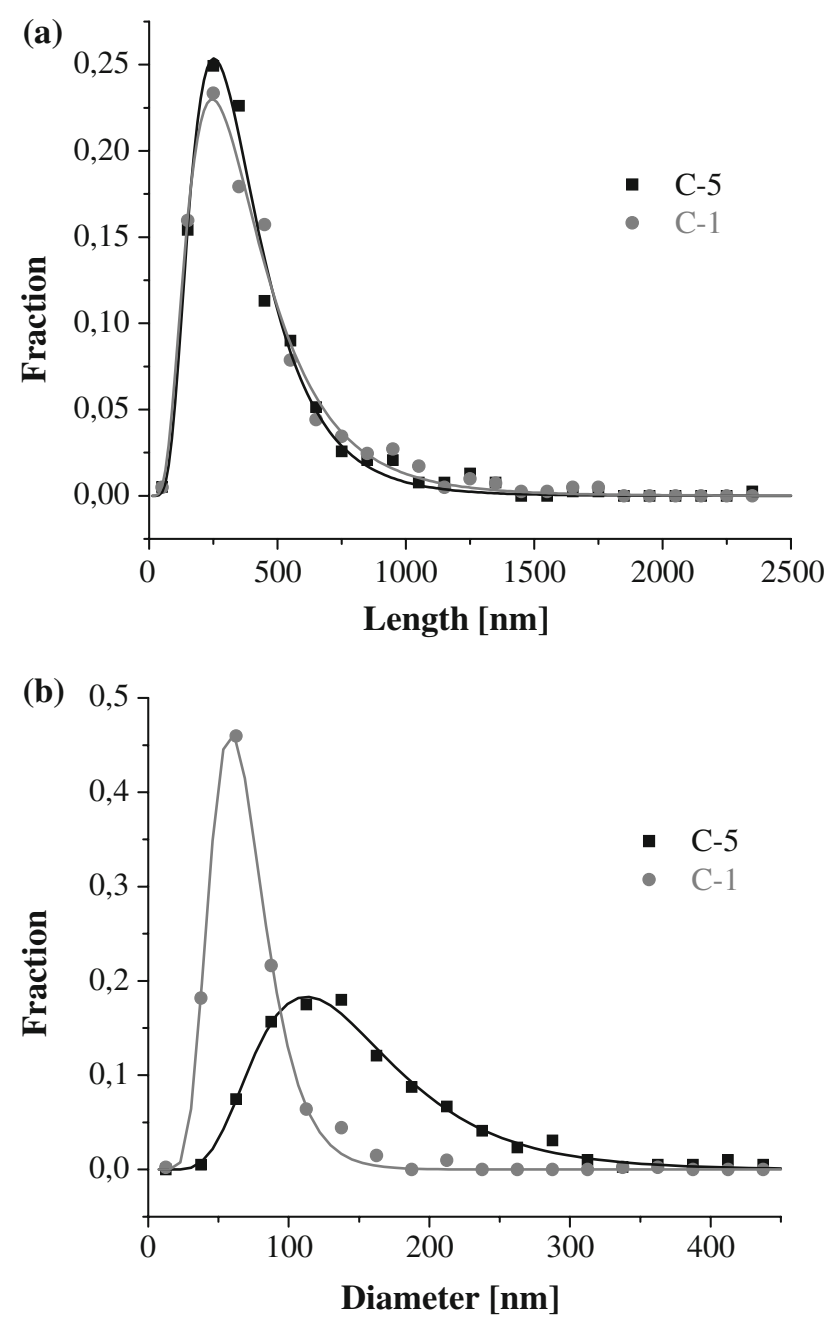

Fig. 15 Shape analysis of two single-phase catalysts heat-treated at different temperatures: distribution of (a) length and (b) the diameter of the M1 needles. single-phase activated at lower temperatures (C1), single-phase activated at higher temperatures (C5)

\section{Summary and Conclusions}

In the last decade, $\mathrm{MoVTeNbO}_{x}$ catalysts, and specifically the M1 phase have generated great academic interest due to the exceptional catalytic performance achieved in the selective oxidation of propane to acrylic acid. The accessibility of phase-pure M1 on a large scale is a key issue that needs to be solved in order to systematically investigate the catalytic properties of M1 and to elucidate the function of its structure in propane activation and oxygenate formation $[3,12,15,17,24]$. Hydrothermal synthesis of the chemically and structurally complex M1 phase requires precise control of the preparation parameters. In this study, the influence of reaction temperature, reaction time, and the technical parameters of the autoclave on morphology, and bulk and local structure of the resulting $\mathrm{MoVTeNbO}_{x}$ catalysts has been investigated, achieving a better understanding of the formation mechanism of the M1 phase, and enabling an improved control over the final catalyst structure.

Hydrothermal reaction is the crucial step in the synthesis of M1. The individual elements are inhomogeneously distributed in the reaction mixture initially introduced into the autoclave as shown by Raman and UV/Vis spectroscopy together with SEM-EDX analysis. In solution, isoand heteropolyanions of molybdenum and giant polyoxometalate clusters have been identified. Pre-precipitation is not necessarily detrimental for formation of phase-pure M1. Investigation of the resulting precursor materials proves that the structural elements required for crystallization of M1 are already established in the course of the hydrothermal process. The reaction could take place by a dissolution-precipitation mechanism involving dissolution or rearrangement of polyoxo metalate building blocks followed by precipitation of an ill-crystallized nano-structured product from solution. A complete reorganization of counter-ion-containing phases is essential, which has been shown to be accelerated in presence of steam at very high temperatures and pressures. Residual ammonium containing supra-molecular species in the precursor result in formation of phase mixtures during the subsequent heat treatment. Precursor materials of phase-pure M1 catalysts show long-range order in the [001] direction as confirmed by XRD and EXAFS analysis. Ordering along the other crystallographic directions is less developed. Crystallization occurs during the subsequent heat treatment of the precursor in an inert gas in the temperature range between 823 and $923 \mathrm{~K}$. The spatial homogeneity of elements in crystalline M1 is already reflected in the corresponding precursor. Remarkably, phase-pure M1 prepared in the present work shows a niobium content twice as high as the $\mathrm{Nb}$ content in the M1 phase analyzed by DeSanto et al. [6], which confirms observations that the M1 structure has a considerable chemical flexibility. There is some indication that the specifics of the needle-like morphology of the final catalyst can be controlled by the conditions of the activation process. An anisotropic growth of the basal (001) plane of the M1-phase has been observed, which is reflected in an increased mean diameter of the needles in materials activated at higher temperature.

In summary, precise control of the hydrothermal reaction conditions is required to obtain the desired crystal structure. The proper conditions can be achieved by optimizing particularly reaction temperature and reaction time. Technical parameters of the autoclave influencing the hydrothermal synthesis, have to be taken into account. The present study shows that application of identical reaction parameters does not necessarily mean that identical materials with comparable catalytic properties will be produced when the reaction is performed in different autoclaves. This 
has to be taken into account when the catalytic behavior of MoVTeNbO ${ }_{x}$ catalysts is compared. The availability of insitu techniques is required and currently under development to monitor the hydrothermal reaction inside the autoclave and to generate quantitative kinetic information.

Acknowledgments The authors thank Mrs. Gisela Lorenz, Mrs. Edith Kitzelmann, and Mrs. Gisela Weinberg for technical assistance. Dr. Andreas Furche is acknowledged for performing the thermal analysis. We are grateful to HASYLAB/Hamburg for providing beamtime for this work.

Open Access This article is distributed under the terms of the Creative Commons Attribution Noncommercial License which permits any noncommercial use, distribution, and reproduction in any medium, provided the original author(s) and source are credited.

\section{References}

1. Ushikubo T, Nakamura H, Koyasu Y, Wajiki S (1995) US Patent 5380,933A to Mitsubishi Kasei Corporation

2. Ushikubo T, Oshima K, Kayou A, Hatano M (1997) Stud Surf Sci Catal 112:473

3. Baca M, Pigamo A, Dubois J-L, Millet JMM (2003) Top Catal 23:39

4. López Nieto JM, Botella P, Solsona B, Oliver JM (2003) Catal Today $81: 87$

5. Inorganic Crystal Structure Database, Fachinformationszentrum (FIZ) Karlsruhe, Germany

6. DeSanto P, Buttrey DJ, Grasselli RK, Lugmair CG, Volpe AF, Toby BH, Vogt T (2004) Z Kristallogr 219:152

7. Millet JMM, Roussel H, Pigamo A, Dubois JL, Jumas JC (2002) Appl Catal A Gen 232:77

8. Tsuji H, Oshima K, Koyasu Y (2003) Chem Mater 15:2112

9. Murayama H, Vitry D, Ueda W, Fuchs G, Anne M, Dubois JL (2007) Appl Catal A Gen 318:137

10. Lundberg M, Sundberg M (1993) Ultramicroscopy 52:429

11. Holmberg J, Grasselli RK, Andersson A (2004) Appl Catal A Gen 270:121

12. Grasselli RK, Buttrey DJ, DeSanto P Jr, Burrington JD, Lugmair CG, Volpe AF Jr, Weingand T (2004) Catal Today 91-92:251

13. Vitry D, Morikawa Y, Dubois JL, Ueda W (2003) Top Catal 23:47

14. Beato P, Blume A, Girgsdies F, Jentoft RE, Schlögl R, Timpe O, Trunschke A, Weinberg G, Basher Q, Hamid FA, Hamid SBA, Omar E, Mohd Salim L (2006) Appl Catal A Gen 307:137
15. Wagner JB, Timpe O, Hamid FA, Trunschke A, Wild U, Su DS, Widi RK, Hamid SBA, Schlögl R (2006) Top Catal 38:51

16. Hibst H, Rosowski F, Cox G (2006) Catal Today 117:234

17. Ueda W, Vitry D, Katou T (2005) Catal Today 99:43

18. DeSanto P Jr, Buttrey DJ, Grasselli RK, Lugmair CG, Volpe AF, Toby BH, Vogt T (2003) Top Catal 23:23

19. DeSanto P Jr, Buttrey DJ, Grasselli RK, Pyrz WD, Lugmair CG, Volpe AF Jr, Vogt T, Toby BH (2006) Top Catal 38:31

20. Ushikubo T, Sawaki I, Oshima K, Inumaru K, Kobayakawa S, Kiyono K (1995) US Patent 5,422,328 to Mitsubishi Kasei Corporation

21. Baca M, Millet JMM (2005) Appl Catal A Gen 279:67

22. Ueda W, Vitry D, Kato T, Watanabe N, Endo Y (2006) Res Chem Intermed 32:217

23. Botella P, Solsona B, Martinez-Arias A, López Nieto JM (2001) Catal Lett 74:149

24. Botella P, López Nieto JM, Solsona IB, Mifsud A, Márquez F (2002) J Catal 209:445

25. Vitry D, Morikawa Y, Dubois JL, Ueda W (2003) Appl Catal A Gen 251:411

26. Ueda W, Vitry D, Katou T (2004) Catal Today 96:235

27. Botella P, García-González E, López Nieto JM, González-Calbet JM (2005) Solid State Sci 7:507

28. Botella P, Concepción P, López Nieto JM, Moreno Y (2005) Catal Today 99:51

29. Ivars F, Botella P, Dejoz A, López Nieto JM, Concepción P, Vázquez MI (2006) Top Catal 38:59

30. Ueda W, Oshihara K (2000) Appl Catal A Gen 200:135

31. Katou T, Vitry D, Ueda W (2003) Chem Lett 32:11

32. Ressler T (1998) J Synchrotron Radiat 5:118

33. Oshihara K, Hisano T, Ueda W (2001) Top Catal 15:153

34. Gupta J (1937) Nature 140:685; Siebert H (1959) Z Anorg Allgem Chem 301:11

35. Evans JC (1963) Inorg Chem 2:373

36. Tytko K-H, Schönfeld B (1975) Z Naturforsch B 30:471

37. Jehng J-M, Wachs IE (1991) J Raman Spectrosc 22:83

38. Müller A, Krickemeyer E, Bögge H, Schmidtmann M, Peters F (1998) Angew Chem Int Ed 37:3360

39. Müller A, Todea AM, van Slageren J, Dressel M, Bögge H, Schmidtmann M, Luban M, Engelhardt L, Rusu M (2005) Angew Chem Int Ed 44:3857

40. Sadakane M, Watanabe N, Katau T, Nodasaka Y, Ueda W (2007) Angew Chem Int Ed 46:1493

41. Pope MT, Jeannin Y, Fournier M (1983) Heteropoly and isopoly oxometalates. Springer-Verlag, Berlin, p 21

42. Yuhao S, Jingfu L, Enbo W (1986) Inorg Chim Acta 117:23

43. Mueller A, Penk M, Krickemeyer E, Boegge H, Walberg HJ (1988) Angew Chem 100:1787

44. Boeschen I, Buss B, Krebs B (1974) Acta Crystallogr B 30:48 